\title{
Health system barriers and levers in implementation of the Expanded Program on Immunization (EPI) in Pakistan: an evidence informed situation analysis
}

\author{
Babar Tasneem Shaikh ${ }^{1 *} \mathbb{D}$, Zaeem ul Haq ${ }^{2}$, Nhan $\operatorname{Tran}^{3}$ and Assad Hafeez ${ }^{1}$
}

\section{* Correspondence:}

shaikh.babar@gmail.com

${ }^{1}$ Health Services Academy, Chak Shahzad, Park Road, Islamabad 44000, Pakistan

Full list of author information is available at the end of the article

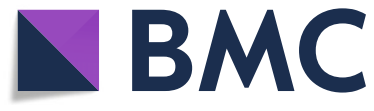

\section{Background}

Despite being an established cost-effective public health strategy for improving child survival, each year, millions of children in low- and middle-income countries (LMICs)

(c) The Author(s). 2018 Open Access This article is distributed under the terms of the Creative Commons Attribution 4.0 International License (http://creativecommons.org/licenses/by/4.0/), which permits unrestricted use, distribution, and reproduction in any medium, provided you give appropriate credit to the original author(s) and the source, provide a link to the Creative Commons license, and indicate if changes were made. The Creative Commons Public Domain Dedication waiver (http://creativecommons.org/ publicdomain/zero/1.0/) applies to the data made available in this article, unless otherwise stated.

Results: Themes generated from the literature review included financing, governance, service delivery, human resources, information systems, and supplies and vaccines. Findings suggest that certain areas in the larger health system need to be improved for a more coordinated implementation of EPI in Pakistan. Moreover, it is imperative to understand community behaviors and perceptions as well as demand side issues in order to achieve the desired results.

Conclusion: For better immunization coverage and ultimately a reduction in child mortality due to preventable diseases, EPI operations and performance must be improved. Further systematic implementation research could help to develop an even finer understanding of the system-wide bottlenecks encumbering the coverage and efficiency of the program.

Keywords: Immunization, Child health, Health system, Pakistan 
do not receive the full series of vaccines on their national routine immunization schedule $[1,2]$. In Pakistan, over 50\% of deaths in post-neonatal children are attributable to pneumonia, diarrhea, or meningitis, which can be prevented through vaccination [3]. The Government of Pakistan initiated the Expanded Program on Immunization (EPI) in 1978 and gradually introduced all requisite antigens, with the recent addition of Rota virus [4]. WHO recommends immunization coverage of $90 \%$ at the national level and at least $80 \%$ for every district [5]. Pakistan's immunization indicators have improved since the program's inception; however, recent data from 2012 to 2013 recorded merely $54 \%$ full immunization coverage for children age 12-23 months (Fig. 1) [6].

Vaccine-specific coverage starting from BCG coverage at $85 \%$ falls to $61 \%$ for measles (Fig. 1). In addition, there is a large dropout seen from the first two doses of polio (90.2\%) and DPT (76.8\%) to third doses of the same vaccines (82 and 62.5\% respectively). Vaccine coverage drops with birth order; first child coverage is $64 \%$, while only $39 \%$ of children born in order 6 or more are fully covered. There are significant regional variations with the Islamabad Capital Territory having the highest percentage (74\%), followed by the provinces of Punjab (66\%) and Khyber Pakhtunkhwa (53\%), whereas immunization coverage is lowest in Sindh province (29\%) and Baluchistan province (16\%). There are obvious differences in immunization coverage between children of women with no education $(40 \%)$ and children of literate mothers (74\%). Children from households in the highest wealth quintile are much more likely to be fully immunized (75\%) as compared to those in the lowest quintile (23\%) [6]. In Punjab, the situation seems to be deteriorating (Fig. 2) with the percentage of fully immunized children age 12-23 months dropping to be 56\% in 2014 [7], whereas Sindh showed improvement with full immunization coverage increasing to $35 \%$ in 2014 [8].

Another national survey from 2014 to 2015 captured a significant gap in the percentage of fully immunized children between rural (56\%) and urban (70\%) areas. The provincial differences demonstrate similar disparity. The data for urban/rural differences by province were in Sindh (62/33\%), Baluchistan (48/20\%), Khyber Pakhtunkhwa (74/54\%), and Punjab (75/65\%). Punjab had the highest immunization rate (70\%) followed by Khyber

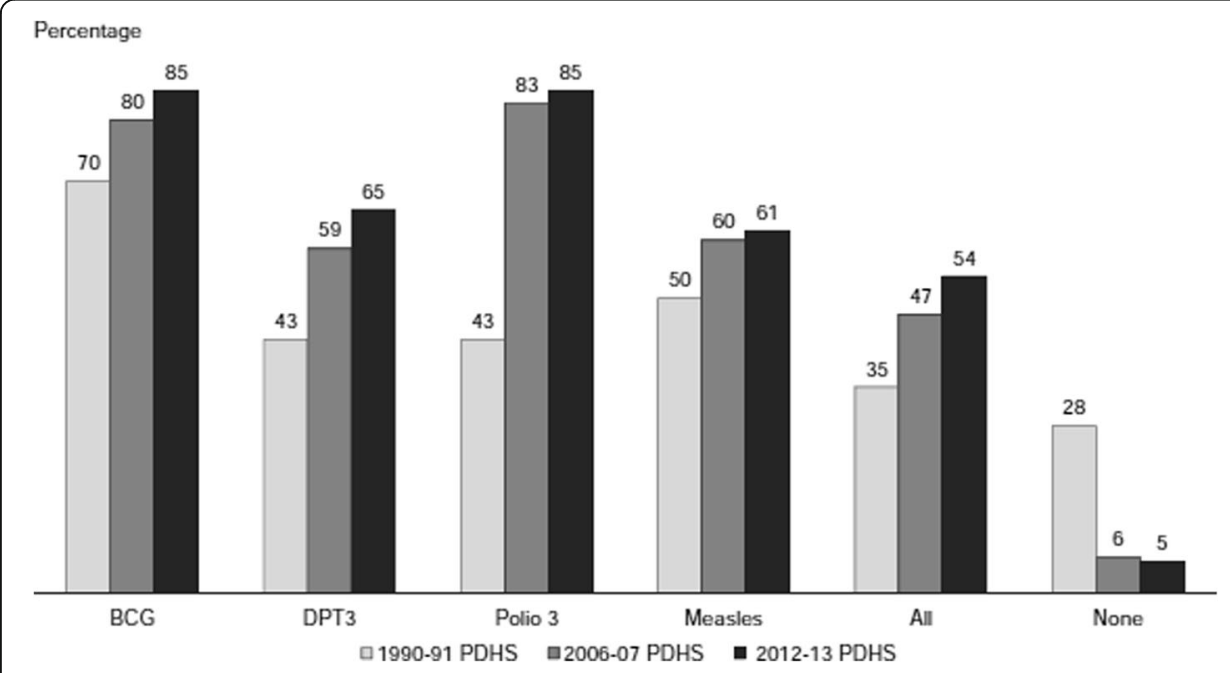

Fig. 1 Trends in immunization coverage among children age 12-23 months. Add the source citation [6] 


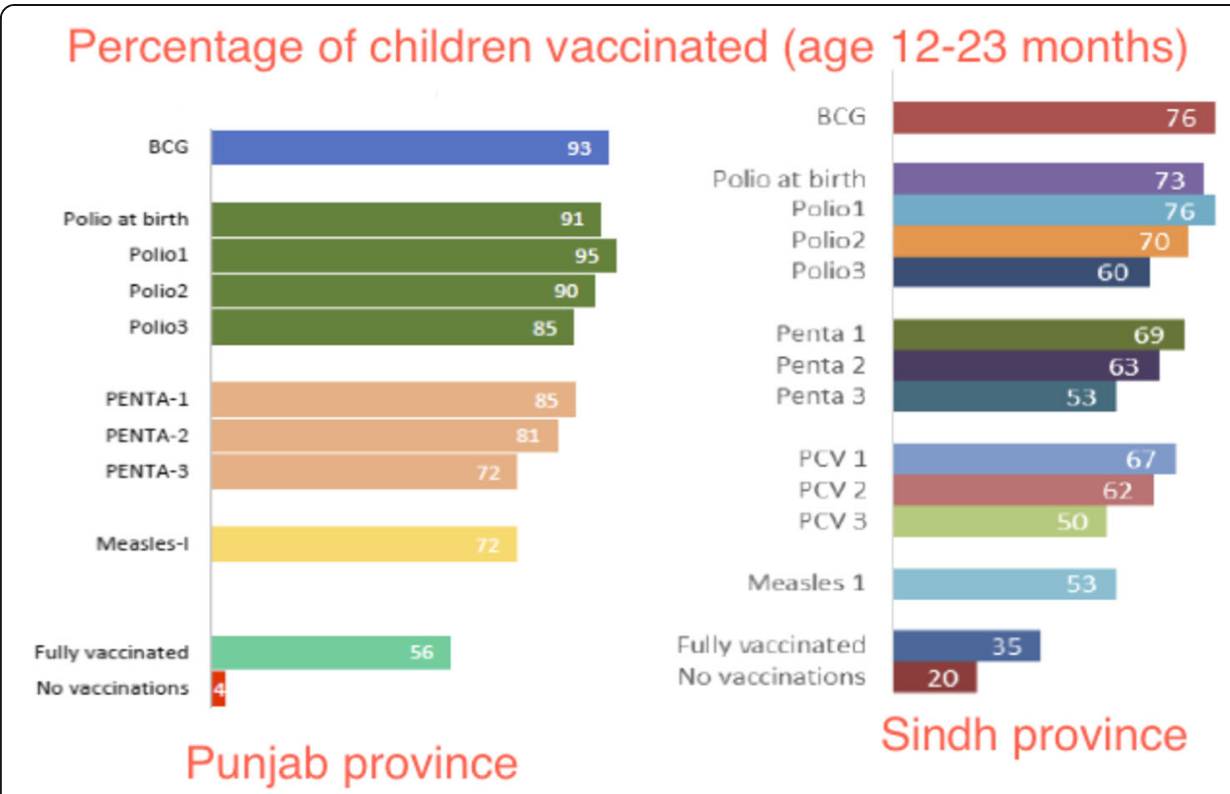

Fig. 2 Vaccination coverage in 2014 for children age 12-23 months in Punjab and Sindh provinces. MICS $2014[7,8]$

Pakhtunkhwa (58\%) and Sindh (45\%). Baluchistan, which is the most deprived area, had the lowest coverage with only $27 \%$ of children fully immunized [9].

Given this state of affairs, it is evident that there is a need to take stock, particularly to understand the health system-wide barriers as well as the levers that could influence progress and thereon develop strategies to either overcome or capitalize on these factors to optimize performance of the EPI program in Pakistan.

\section{Methods}

This study aims at bridging the information gaps about system-level barriers that currently are impeding the optimal delivery of immunization services to the children of Pakistan. We employed the basic tenets of WHO's health systems strengthening framework, i.e., governance, financing, service delivery, human resource, information systems, and essential drugs, supplies, and technologies [10], and Sallis' socio-ecological model which helps in studying the community's perceptions and behaviors [11]. Hence, this study explored various pillars of the immunization program in Pakistan from both the service delivery and the demand side perspective. We conducted a detailed literature review to document what has been published already about this topic, identified barriers and levers of EPI implementation, and then developed a set of recommendations. Using MeSH terms and key words (Immunization; Child health; Health system; Pakistan), relevant peer-reviewed articles were accessed using PubMed and Google Scholar. Other reports and documents were accessed from the websites of EPI Pakistan and UN agencies. Salient areas emerging from the literature review were cataloged under the building blocks of the health system.

\section{Results}

The information gleaned from the peer-reviewed articles, government reports, EPI documents, WHO/UNICEF/GAVI reports, and some gray literature unravels a stagnant or 
declining immunization status. At the same time, this analysis also shows a multifactorial picture responsible for the current state of affairs of EPI in Pakistan.

\section{Program financing}

Development partners have always generously supported the maternal, child, and newborn health programs in Pakistan [12]. Although the immunization program mainly depends upon domestic development funds, resources from donors (WHO, UNICEF, GAVI, etc.) have been instrumental too. Pakistan is the biggest recipient of GAVI at present, categorized as a Tier 1 priority country. GAVI financial support to the Pakistan government has been channeled through partner organizations, predominately, WHO and UNICEF [13]. The Government of Pakistan's own share represents approximately $20 \%$ of the total EPI allocations [4]. The Japan International Cooperation Agency (JICA) and the World Bank also support the program. Moreover, the donors have supported in-service trainings for EPI managers. However, delayed release of funds and inefficiencies in expenditure have been noted as some key issues in the past. Of particular note is the lack of appropriation for transportation and fuel costs. Shortage of funds for repair and maintenance of cold chain equipment and vehicles could jeopardize vaccine efficacy [13].

\section{Program governance}

Pakistan went through devolution of its service-related public sectors including health sector with the 18th amendment in its constitution effective from June 28, 2011. The Federal Ministry of Health $(\mathrm{MoH})$ was dissolved, and the overall responsibility for health services policy direction and planning was devolved to the provinces [14]. Inefficiencies and stalled health system's performance was observed at nearly all of the operational levels for some time after the devolution of 2011 [15]. A lack of clarity in roles and responsibilities of federal and provincial tiers of the government resulted in a vacuum in governance and weak stewardship at decision-making levels. The National Health Vision 2016-2025 later outlined more clearly the roles and responsibilities of the federal and provincial government vis-à-vis health programs and interventions [16]. There is a proposal that going forward, each district must have its own EPI implementation plan, which should consider and address the gaps identified by the situational assessment [13]. Polio in Pakistan has generated much analysis and discussion at the global and national levels. In late 2014, due to a rise in polio cases, an Emergency Operations Centre was established and was mandated to ensure a synergy between the Polio Eradication Initiative and EPI, as well as with other sectors. Nevertheless, this convergence or synergy is still to be seen as fully operational [17]. The role of the private sector as a key stakeholder has also been documented with regard to governance of EPI [18], which could work hand in hand with the public sector in order to achieve the desired targets of immunization, but its potential still remains untapped.

\section{Human resource}

The lack of a comprehensive human resource (HR) strategy has been discussed time and again in the context of EPI in Pakistan. There is no regular and formal training program for the management cadres, and learning is mostly self-directed and on the 
job. Managers often lack the practical knowledge for leading program operations proficiently [19]. EPI workers' fatigue due to frequent polio campaigns have reduced their time dedicated to routine EPI vaccination initiatives [13]. In-service training for routine immunization staff is not held on the basis of any planning and programming, rather it is conducted whenever the donor funding is available. Competency of the staff, outreach capacity, service structure, attitudes towards clients, political interference in transfers and postings, and lack of accountability are all notable HR-related issues of EPI $[20,21]$. On the other hand, there are workers in the polio program who are willing to perform their duties while putting their lives at risk, and facing extremist sections of the society, amidst a grim law and order situation [22]. Introducing incentive structures among managers and health workers of EPI or contracting with non-governmental organizations (NGOs) can potentially improve the HR performance [23].

\section{Service delivery}

Immunization services provided through outreach are costly and face logistic issues. The outreach strategy of EPI lacks details in micro-plans, has weak monitoring and supervision, and deficient human, operational, and other resources [13]. In many rural areas, routine immunization literally comes to naught during National Immunization Days, when all vaccinators are entrusted with the additional responsibility of covering 150-200 children per day, door marking, record keeping in tally sheets, and locating and marking missing children [24]. Coverage of vaccination services requires a rational re-deployment of vaccinators and task shifting to community-based service providers, e.g., lady health workers (LHWs) and community midwives for covering their catchment areas. Vaccinators would thus be able to focus on areas not covered by any workers [25]. Involvement of the private sector and NGO outlets is also one of the solutions, but at present, there is no policy in EPI on formal engagement with the private sector [13].

\section{Supplies and vaccines}

Interrupted supply of vaccines has been reported from time to time. Delays in forecasting, procurement, storage, and distribution to the provinces, districts, and to the "last mile" (i.e., the hardest to reach segments of the population) have suffered in the past because of unduly tedious procedures [13]. Inadequate maintenance of cold chain is another issue reported in the literature. Power outages are frequent, and there is no electricity back up at many places. EPI has state-of-the-art cold chain for vaccine storage and transport; however, its maintenance has been a long-standing issue, particularly in rural remote areas where program monitoring is also weak [26]. Alternative solutions such as solar energy ought to be tried as a backup for power outages.

\section{Information systems}

Unreliable reporting, poor monitoring and supervision systems, and limited use of local data for decision-making are other impediments in the performance of EPI. Data collection is paper-based at the facility level, and then, from district upwards, it becomes electronic. Therefore, establishing its credibility has been a challenge. Moreover, for quite some time, the EPI data was not reflected in the District Health Information System (DHIS) [27]. Inaccurate immunization records lead to the loss of billions of rupees 
every year [15]. There is a dearth of health systems research to better understand the dynamics between EPI and the beneficiary population [28].

\section{Community perceptions and behaviors}

Low community awareness and misbeliefs that vaccines cause disease and the doubts about vaccine safety and effectiveness have been reported as important factors, impeding the uptake of immunization, especially in the case of polio [29]. Therefore, educating the masses and population segments with low literacy levels, especially the women, is a must for improving the utilization of immunization services [30]. Gender differential in immunization coverage needs innovative gender mainstreaming strategies at the community level such as employing more female vaccinators and community volunteers for outreach to women [31]. Community activists can also encourage people to seek immunization services and can increase demand through educating various community segments [32]. Communication between immunization workers and the parents of children has been flawed, and a positive engagement has helped with overcoming the resistance to vaccinations [33]. On the other hand, service providers in clinics do not emphasize the importance of immunization [34]. Religious beliefs and lack of knowledge about the benefits of the vaccines still dictate many pockets of this highly diverse and populated country [35]. Targeted community awareness programs, a robust surveillance network, and engagement with the dominant religious entities can help to root out the issue $[36,37]$. Better understanding of the religion and soliciting local support for vaccination campaigns may assist in negotiating access in the areas where refusal is an issue [38].

Demand side issues and community misperceptions are quite high. Ample funds are allocated for social mobilization, yet meager amounts are spent on communication, and to create community awareness of routine immunization [13]. Moreover, a shift of resources from mass media (TV and radio) to community-level, dialogic communication is proposed, given clear evidence that caregivers rely on healthcare providers, family, and friends for information about immunization [17]. The demand and supply barriers of EPI have been well summarized (Table 1) in an important study undertaken by UNICEF [39].

\section{Discussion and recommendations}

There are several factors which we can bank upon for improving the EPI immunization program in Pakistan: provincial autonomy as called for in the 18th constitutional

Table 1 Demand and supply side barriers in effective implementation of EPI

\begin{tabular}{ll}
\hline Issues & $\begin{array}{l}\text { Demand/supply } \\
\text { side barriers }\end{array}$ \\
\hline $\begin{array}{l}\text { 1. Low awareness level among caregivers and healthcare providers regarding } \\
\text { vaccine-preventable diseases and their risks }\end{array}$ & Demand \\
2. Concerns of caregivers about safety of oral polio vaccine & Demand \\
$\begin{array}{l}\text { 3. Belief in and use of local remedies for prevention and treatment } \\
\text { 4. Low knowledge and awareness of health care workers regarding VPDs }\end{array}$ & $\begin{array}{l}\text { Demand and supply } \\
\text { and their prevention }\end{array}$ \\
$\begin{array}{l}\text { 5. Distance, time, and cost of travel to health facility and long waiting time there } \\
\text { 6. Unavailability of vaccines and vaccinators and dissatisfaction with quality of service }\end{array}$ & Demand and supply \\
7. Missing vaccination card in the home & Demand and supply \\
\hline
\end{tabular}


amendment, re-enactment of a national ministry of health for coordination, the infrastructure needed for the polio program, and the renewed focus of the government and the development partners on routine immunization. No program, however, can improve without looking at it insightfully and searching for the underlying factors that may be the reason for its sub-optimal performance. Our literature review has unraveled some important areas that need further exploration. These areas along with key recommendations are summarized here for future research and to broaden the evidence base for the immunization program in Pakistan and elsewhere.

\section{Financing and resource allocation}

The budgetary allocations, spending, and reporting have to be made more efficient. Switching over to a midterm budgetary framework mode could be a good option for EPI. This mode of financing will be performance-based and target-oriented. Funds must be earmarked for the maintenance of cold chain, which is the most vital component of the entire program.

\section{Program governance, management, and accountability}

The role of the federal ministry of health and federal EPI cell in the overall coordination of immunization services in the country is pivotal. Forums for "interprovincial coordination" and "donor coordination" must be established. Program review meetings held regularly at the federal, provincial, district, and health facility levels may help to improve governance of the program. Involving the private sector can also resolve some governance issues. Furthermore, participation of local organizations, community leaders, and volunteers can provide timely feedback to improve the immunization services.

\section{Capacity building and human resource}

A fresh review and mapping of the EPI HR and their capacity is required for chalking out a plan for an in-service training. This exercise will bring to light the HR gaps at the federal and provincial EPI cells and there lead to recruitment of new vaccinators and women volunteers at the community level. This may help to reduce workload on the existing staff and perhaps task shift to some extent.

\section{Immunization policy and legislation for service delivery}

Private sector, which is the first contact of care seeking for $80 \%$ of the population in Pakistan and which is perceived as more trustworthy, must also be engaged for the delivery of routine immunization. This engagement will have the potential to improve access as well as coverage. Likewise, if task shifting to LHWs is required, legislation and policy decisions must be taken expeditiously. The program needs a clear strategy on immunization through outreach as well as fixed centers. Integration of EPI with other public health interventions such as breastfeeding, maternal nutrition, community midwifery, and micronutrients must be considered.

\section{Information systems}

EPI data reliability ought to be enhanced through a critical review of the current reporting system and by objectively examining the procedures, roles, and 
responsibilities and also the reasons for its under-performance. Employing newer technologies (i.e., GPS, tablets, smart phones, etc.) can potentially improve the timeliness and accuracy of the data.

\section{Engaging communities}

Campaigns for demand creation need careful planning and coordination with communication experts. Increase in the allocation of funds for mass campaigns, and to the districts to customize messages in their local context, is needed. Developing a deeper understanding of locally held perceptions or misperceptions that shape the behaviors of the community will be helpful in certain geographical areas that have historically proved resistant to EPI efforts. Face-to-face communication and advocacy with local opinion leaders and community elders should be continued.

\section{Risk analysis}

Periodic assessment of the high risk, high priority districts and mapping of vulnerable populations must be carried out. Similarly, profiling of HR and logistic gaps is imperative. Timely and correct interpretation of risk analysis is vital for designing context-specific interventions. Community's role in disease surveillance must also be tapped for early case detection and reporting, initiating an immediate response, and improving outcomes.

\section{Conclusion}

Our literature review unraveled a multifactorial picture responsible for insufficient immunization coverage in Pakistan. Current evidence suggests that focusing on governance of the program, improving facility-based service delivery and addressing community perceptions could result in the biggest payoffs. Within a multi-cultural milieu and a complex health system, the country presents an ideal case for embarking upon more systematic health systems and implementation research to develop an empirical evidence base and to re-build the routine immunization program to serve the people who are most in need. Moreover, university-conducted research must reach implementers. The current situation pleads the case for generating fresh evidence in order to review policy, programmatic approach, service delivery, and stakeholder engagement for improving EPI in Pakistan.

\footnotetext{
Abbreviations

BCG: Bacillus Calmette-Guérin; DHIS: District Health Information System; EPI: Expanded Program on Immunization; GAVl: Global Alliance for Vaccines and Immunization; GPS: Global Positioning System; HR: Human resources; JICA: Japan International Cooperation Agency; LHW: Lady health workers; LMICs: Low- and middle-income countries; NGOs: Non-governmental organizations; UNICEF: United Nations Children's Fund; WHO: World Health Organization
}

Authors' contributions

BTS and ZH were responsible for the overall manuscript preparation. BTS conducted most of the literature search and did the compilation. ZH contributed to the write-up of various drafts. NT and AH added intellectual content to the successive drafts. All the authors approved the final draft.

Ethics approval and consent to participate

Not applicable.

Consent for publication

Not applicable. 


\section{Publisher's Note}

Springer Nature remains neutral with regard to jurisdictional claims in published maps and institutional affiliations.

\section{Author details}

${ }^{1}$ Health Services Academy, Chak Shahzad, Park Road, Islamabad 44000, Pakistan. ${ }^{2}$ Johns Hopkins Center for Communication Programs, Islamabad, Pakistan. ${ }^{3}$ Alliance for Health Systems and Policy Research, Geneva, Switzerland.

Received: 27 December 2017 Accepted: 8 June 2018

Published online: 17 September 2018

\section{References}

1. Adre FE, Booy R, Bock HL, et al. Vaccination greatly reduces disease, disability, death and inequity worldwide. Bull World Health Organ. 2008;86:140-6

2. Oyo-Ita A, Wiysonge CS, Oringanje C, Nwachukwu CE, Oduwole O, Meremikwu MM. Interventions for improving coverage of childhood immunization in low- and middle-income countries. Cochrane Database Syst Rev. 2016;7: CD008145

3. UNICEF. Progress for children beyond averages. Learning from the MDGs. In: New York; 2015

4. Government of Pakistan. Comprehensive multi-year plan, 2014-2018. Expanded program on immunization, Pakistan. Ministry of National Health Services, Regulations \& Coordination, Islamabad: 2014

5. World Health Organization. Immunization coverage. In: Fact sheet; 2016.

6. National Institute of Population Studies \& Macro International. Pakistan Demographic \& Health Survey 2012-13. Islamabad: National Institute of Population Studies \& Macro International; 2013.

7. Bureau of Statistics \& UNICEF. Punjab multiple indicator cluster survey 2014. Lahore: Planning \& Development Department, Government of Punjab: 2015.

8. Bureau of Statistics \& UNICEF. Sindh multiple indicators clusters survey 2014. In: Planning \& Development Department; 2015.

9. Bureau of Statistics. Pakistan standards of living measurement survey 2014-15. Islamabad: Statistics Division, Government of Pakistan; 2015.

10. World Health Organization. Everybody business-strengthening health systems to improve health outcomes: WHO's framework for action. In: Geneva; 2007.

11. Sallis et al. Ecological models of health behavior. In: Glanz, et al., editors. Health behavior and health education: theory and practice. 4th ed; 2008.

12. Rabbani F, Shaikh BT, Mazhar MA. Role of development partners in Maternal, Newborn \& Child Health (MNCH) programming in the post reform times: a descriptive qualitative study from Pakistan. BMJ Open. 2015;e008665:5

13. GAVI \& Government of Pakistan. Pakistan: Joint appraisal report. Islamabad: GAVI \& Government of Pakistan; 2016.

14. World Health Organization. Pakistan-health workers for all and all for health workers. http://www.who.int/ workforcealliance/countries/pak/en/. Global Health Workforce Alliance. Geneva.

15. Shaikh BT, Hafeez A. Strengthening health system with key strategies in the post devolution times in Pakistan. Position Paper Series No. 2. Islamabad: Health Services Academy; 2012.

16. Ministry of National Health Services, Regulations \& Coordination. National Health Vision 2016-2025. Government of Pakistan. Islamabad: 2016.

17. Advance Communication Transform Society, LLC. Pakistan. Communication Strategy for Routine Immunization, 2015-2018. Government of Pakistan \& UNICEF. Islamabad: 2015.

18. Mangrio N, Alam MM, Shaikh BTI. Expanded program on immunization doing enough? Viewpoint of health workers and managers in Sindh. Pakistan J Pak Med Assoc. 2008;58(2):64-7.

19. Hasan Q, Bosan AH, Bile KM. A review of EPI progress in Pakistan towards achieving coverage targets: present situation and the way forward. East Mediterr Health J. 2010;16(Suppl):S31-8.

20. Pakistan Institute of Legislative Development and Transparency (PILDAT). Immunization in Pakistan. Briefing pape no. 37. In: Islamabad: Pakistan Institute of Legislative Development and Transparency (PILDAT). Immunization in Pakistan; 2010

21. Bukhari HT, Ibrahim M, Bukhaari KT, Zafar H. A systematic review to identify the factors for partial vaccination in children. J Islamabad Med Dent Coll. 2016;5(1):45-7.

22. Wain ZN, Masood RA, Ali RW, Bashir I. An overview of immunization practices in Pakistan. Int Current Pharm J. 2016;5(11):94-6.

23. Loevinsohn B, Hong R, Gauri V. Will more inputs improve the delivery of health services? Analysis of district vaccination coverage in Pakistan. Int J Health Plann Manag. 2006;21:45-54.

24. Mangrio N, Shaikh BT, Alam MM. Issues and challenges in expanded program on immunization in Sindh. Pakistan J Coll Physicians Surg Pak. 2007;17(5):308.

25. Husain S, Omer SB. Routine immunization services in Pakistan: seeing beyond the numbers. East Mediterr Health J. 2016;22(3):201-11.

26. Civil Society Human and Institution Development Program. Barriers to immunization in Pakistan. The CSOs perspective. Karachi: Civil Society Human and Institution Development Program. Barriers to immunization in Pakistan; 2012.

27. Mushtaq MU, Shahid U, Majrooh MA, et al. From their own perspective-constraints in the polio eradication initiative: perceptions of health workers and managers in a district of Pakistan's Punjab province. BMC Int Health Hum Rights. 2010;10:22.

28. Shaikh BT, Alizai AA. Confronting the challenge of improving routine immunization in Pakistan: the need and importance of health systems research. Pak J Public Health. 2012;2(3):4-9.

29. Toole MJ. So close: remaining challenges to eradicating polio. BMC Med. 2016;14:43.

30. Bugvi AS, Rahat R, Zakar R, et al. Factors associated with non-utilization of child immunization in Pakistan: evidence from the demographic and health survey 2006-07. BMC Public Health. 2014;14:232. 
31. Jones N, Walsh C, Buse K. Gender and immunization. A Report Commissioned by the GAVI Alliance Secretariat London: 2008

32. Ryman TK, Dietz V, Cairns KL. Too little but not too late: results of a literature review to improve routine immunization programs in developing countries. BMC Health Serv Res. 2008;8:134

33. Salim F. Culture, politics, and religion: exploring resistance to vaccinations in South Asia. Hum Welfare. 2012;1:91-104.

34. Khowaja AR, Zaman U, Feroze A, et al. Routine EPI coverage: sub-district inequalities and reasons for immunization failure in a rural setting in Pakistan. Asia Pac J Public Health. 2015;27(2):NP1050-9.

35. Khan MU, Ahmad A, Aqeel T, et al. Knowledge, attitudes and perceptions towards polio immunization among residents of two highly affected regions of Pakistan. BMC Public Health. 2015;15:1100.

36. Hussain SF, Boyle P, Patel P, Sullivan R. Eradicating polio in Pakistan: an analysis of the challenges and solutions to this security and health issue. Glob Health. 2016;12:63.

37. Ghafoor S, Sheikh N. Eradication and current status of poliomyelitis in Pakistan: ground realities. J Immun Res. 2016:6837824:6.

38. Nishtar S. Pakistan, politics and polio. Bull World Health Organ. 2010;88:159-60.

39. UNICEF. KAPB-National. A study to identify drivers of inequities and barriers to access and utilization of immunization services for improved immunization coverage and outcomes in Pakistan, Islamabad: 2014.

Ready to submit your research? Choose BMC and benefit from:

- fast, convenient online submission

- thorough peer review by experienced researchers in your field

- rapid publication on acceptance

- support for research data, including large and complex data types

- gold Open Access which fosters wider collaboration and increased citations

- maximum visibility for your research: over $100 \mathrm{M}$ website views per year 